\title{
Criação e distribuição de valor na indústria cearense de alimentos: estudo nas companhias listadas na Bovespa no período (2008-2014)
}

\author{
Ana Cristina de Moura Silva \\ Universidade de Fortaleza \\ Brasil \\ Mônica Mota Tassigny \\ Universidade de Fortaleza \\ Brasil
Maria da Graça de Oliveira Carlos
Universidade de Fortaleza
Brasil \\ Fabiana Pinto de Almeida Bizarria \\ Universidade de Fortaleza \\ Brasil \\ Lorena Aragão Feitosa \\ Universidade de Fortaleza \\ Brasil
}

Data de submissão: 20/06/2016

Data de aceite: 05/02/2018

\section{RESUMO}

O Valor Adicionado corresponde ao patrimônio criado por uma empresa em um determinado período. Este trabalho tem por objetivo analisar a criação e distribuição do valor adicionado apresentados na Demonstração do Valor Adicionado. Para esse fim, realizou-se pesquisa descritiva, documental e exploratória, mediante coleta de dados nas demonstrações financeiras das empresas de alimentos listadas na BM\&FBovespa, a fim de evidenciar seu desenvolvimento nos anos de 2008 a 2014 do seu valor adicionado e seu percentual de adição com relação a seu PL, Lucro Líquido e Ativos Totais. Os rendimentos indicam grande relevância das informações geradas por este demonstrativo para os agentes econômicos interessados nessas empresas desse setor. 
Palavras-chave: Demonstração do Valor Adicionado. Indústria de Alimentos. Informação.

\begin{abstract}
The Value Added corresponds to the equity created by a company in a given period. This work aims to analyze the creation and distribution of added value presented in the Statement of Value Added. To this end, there was descriptive, documentary and exploratory research by collecting data on the financial statements of food companies listed on the BM \& FBovespa, in order to demonstrate its development in the years 2008-2014 of its added value and its addition of percentage with respect to its PL, Net Income and Total Assets. Yields indicate great importance of the information generated by this statement for economic agents interested in these companies in this sector.
\end{abstract}

Keywords: Statement of Value Added. Food industry. Information.

\title{
1 INTRODUÇÃO
}

A contabilidade é uma ciência que fornece informações sobre a situação econômica e financeira de uma empresa. E, por intermédio das demonstrações contábeis, ela pode se comunicar com os diversos tipos de usuários que necessitam das informações contábeis como, por exemplo, fornecedores, clientes, empregados e outros.

A Lei $n^{\circ} 6.404 / 76$ que trata das Sociedades por Ações, foi modificada pela lei $n^{\circ}$ 11.638/2007 onde alterou a elaboração e a divulgação de demonstrações financeiras, e em seu um artigo 176 dispõe: ao fim de cada exercício social, a diretoria fará elaborar, com base na escrituração mercantil da companhia, as seguintes demonstrações financeiras, que deverão exprimir com clareza a situação do patrimônio da companhia e as mutações ocorridas no exercício. Assim, as demonstrações contábeis são elaboradas segundo informações retiradas de documentos e registros que formam o sistema contábil de uma empresa.

As demonstrações contábeis representam a estrutura da posição patrimonial e financeira, do desempenho e das mudanças na posição financeira da entidade (GUERRA, 2015), e busca atender necessidades informacionais de usuários externos, como, por exemplo, acionistas, administradores, governo e sociedade, que não se encontram em condição de requerer relatórios especificamente planejados para atender as necessidades peculiares (CPC 26; OLIVEIRA et al., 2014; IUDÍCIBUS; MARION; FARIAS, 2009).

Em relação à demonstração financeira (contábil), o balanço patrimonial, formado pelos elementos Ativo e Passivo, sendo que o Ativo é composto dos bens e os direitos, enquanto no Passivo encontram-se as obrigações e o patrimônio, deve compreender todos os bens e direitos, tanto tangíveis (materiais) como intangíveis (imateriais), as obrigações e o 
Patrimônio Líquido da entidade, levantados a partir dos resultados contábeis no livro Razão (NBC-T-3.2). Dessa forma, por meio do Balanço Patrimonial evidencia-se, quantitativamente, em uma determinada data, a posição patrimonial e financeira da entidade (RIBEIRO, 2012), representando um juízo de valor, a medida que "pressupõe a avaliação dos bens sociais mediante critérios que a lei não poderia deixar ao arbítrio do administrador e de seu contador". (LATORRACA, 2000, p. 193).

Ainda no que diz respeito à demonstração financeira, têm-se: a Demonstração do Resultado do Exercício (DRE), representada pelas operações realizadas pela empresa, durante o exercício social, demonstradas de forma a destacar o resultado líquido do exercício (IUDÍCIBUS; MARTINS; GELBCKE, 2000) (Lucro ou Prejuízo); e a Demonstração do Resultado Abrangente (DRA), elaborada com base na soma do resultado líquido apresentado na DRE com outros resultados abrangentes.

As Demonstrações das Mutações do Patrimônio Líquido (DMPL), representa a demonstração contábil destinada a evidenciar, em determinado período, a movimentação das contas que integram o patrimônio da entidade (OLIVEIRA et al., 2014; REIS, 2009), ao passo que evidencia a mutação do patrimônio líquido em termos globais (novas integralizações de capital, resultado do exercício, ajustes de exercícios anteriores, dividendos reavaliação etc.) e em termos de mutações internas (incorporações de reservas ao capital, transferências de lucros acumulados para reservas e vice- versa) (IUDÍCIBUS; MARTINS; GELBCKE, 2000).

As Demonstrações do Fluxo de Caixa (DFC), por sua vez, obrigatória de acordo com a lei $\mathrm{n}^{\mathrm{o}}$ lei 11.638, "tem como objetivo primário prover informações relevantes sobre os pagamentos e recebimentos em dinheiro, de uma empresa, ocorridos durante um determinado período". (IUDÍCIBUS et al., 2010, p.567). A DFC “evidencia a variação do grupo Disponível da sociedade entre dois exercícios sociais consecutivos. O grupo Disponível compreende a soma dos saldos das contas Caixa, Bancos e Aplicações Financeiras de Liquidez Imediata". (VICECONTI; SILVÉRIO, 2013, p. 272).

Além das Demonstrações financeiras, têm-se a categoria de Notas Explicativas, que "visam a complementar as demonstrações contábeis e informar os critérios utilizados pela empresa, a composição dos saldos de determinadas contas, os métodos de depreciação, os principais critérios de avaliação dos elementos patrimoniais e outros". (RIBEIRO, 2012, p.448). Portanto, as Notas possuem a finalidade de complementar as informações das demonstrações contábeis, um resumo das políticas contábeis significativas e outras informações elucidativas (IUDÍCIBUS; MARION, FARIA, 2009). 
O Valor Adicionado, por sua vez, corresponde ao patrimônio criado por uma empresa em um determinado período. Este valor é expresso em termos de Demonstração do Valor Adicionado (DVA), que "compreende todo um conjunto de informações de natureza econômica, que visa demonstrar o valor da riqueza gerada pela empresa e a distribuição para os elementos que contribuíram para sua geração". (DE LUCA, 2009, p.22). A DVA possui como "principal objetivo demonstrar o grau de envolvimento da empresa em relação à sociedade que a acolhe, devendo ser entendido como um instrumento no processo de reflexão sobre as atividades das empresas e dos indivíduos no contexto da comunidade como um todo" (VELTER; MISSAGIA, 2011, p. 381).

As informações contábeis confiáveis e transparentes que são procuradas pelas pessoas que estão envolvidas na elaboração das mesmas e também por aquelas pessoas que necessitam por informações que as auxiliem em suas tomadas de decisões, foi resultante da obrigatoriedade da publicação da DVA pelas companhias de capital aberto.

Assim, diante das conceituações levantadas, têm-se a indústria de alimentos brasileira, responsável por quase $15 \%$ do faturamento do setor industrial e por empregar mais de 1 milhão de pessoas, tem conseguido seguir as tendências internacionais na área de produção, mas ainda precisa desenvolver trajetórias mais consistentes na área de inovação (GOUVEIA, 2006).

A pesquisa visa contribuir com área contábil, à medida que explora o demonstrativo financeiro com suporte na obrigatoriedade de sua publicação. Assim pretende-se responder ao seguinte questionamento: Qual o valor adicionado pelas Indústrias Cearenses do setor alimentício cearense listadas na BM\&FBovespa no período de 2008 a 2014? Para tanto, objetiva-se determinar a criação e distribuição do valor adicionado nas indústrias do setor alimentício cearense, listadas no site da Bolsa de Valores de São Paulo (BM\&FBovespa).

\section{Demonstração do Valor Adicionado, Fundamentos e Modelos}

A DVA surgiu na Europa, principalmente por influência da Inglaterra, França e Alemanha e tem sua publicação recomendada expressamente pelas Organizações das Nações Unidas (ONU) (PADOVEZE, 2009, p. 206). No Brasil, a Lei $\mathrm{n}^{\circ}$ 11.638/07, que introduziu alterações à Lei $n^{\circ}$ 6.404/76, tornou obrigatória, para as companhias de capitais abertas, a elaboração e divulgação da DVA como parte das Demonstrações contábeis divulgadas ao final de cada exercício (IUDÍCIBUS et al., 2010, p. 583). Além disso, a Comissão de Valores Mobiliários (CVM) incentiva desde do início dos anos de 1990, por meio do Parecer de 
Orientação CVM no 24/92 a divulgação da DVA pelas principais sociedades anônimas de capital aberto que operam no mercado brasileiro (RIBEIRO, 2012, p. 409).

Demonstração do Valor Adicionado (DVA) está fundamentada em conceitos macroeconômico, buscando apresentar a parcela de contribuição que a entidade tem na formação do Produto Interno Bruto (PIB) do país (DE LUCA, 1998; GUERRA, 2015). Tem por objetivo demonstrar o valor da riqueza econômica gerada pelas atividades da empresa como resultante de um esforço coletivo e sua distribuição entre os elementos que contribuíram para a sua criação (IUDÍCIBUS et al., 2010) por meio de seus indicadores (quadro 1). Desse modo, a DVA acaba por prestar informações a todos os agentes econômicos interessados na empresa, tais como os empregados, clientes, fornecedores, financiadores e governo (VICECONTI; NEVES, 2013).

\section{Quadro 1 - Os indicadores da DVA}

\begin{tabular}{|c|c|}
\hline Indicador & Definição \\
\hline $\begin{array}{l}\text { Análise Vertical e } \\
\text { Horizontal }\end{array}$ & $\begin{array}{l}\text { Destina-se a evidenciar a tendência evolutiva dos itens da DVA ao longo do tempo, } \\
\text { enquanto a análise vertical procura destacar a estrutura de composição de cada valor } \\
\text { em relação a um total. }\end{array}$ \\
\hline $\begin{array}{l}\text { Indicadores de } \\
\text { geração de riqueza }\end{array}$ & Fornecem informações sobre a capacidade da empresa para criar riqueza. \\
\hline $\begin{array}{l}\text { Potencial do Ativo } \\
\text { para gerar riqueza } \\
\text { (PAGR) }\end{array}$ & $\begin{array}{l}\text { Evidencia a capacidade do Ativo Total da empresa na geração de riquezas. Na forma } \\
\text { de índice, mede quanto cada real investido no Ativo contribuiu na geração do Valor } \\
\text { Adicionado que será distribuído pela empresa. } \\
\qquad \text { PAGR = (Valor Adicionado /Ativo Total) X } 100\end{array}$ \\
\hline $\begin{array}{l}\text { Potencial dos } \\
\text { empregados para } \\
\text { gerar riqueza (PEGR) }\end{array}$ & $\begin{array}{l}\text { Mostra quanto cada empregado contribui, em média, na geração da riqueza da } \\
\text { empresa. Ou seja, quando cada empregado gerou, efetivamente, de riqueza para a } \\
\text { empresa. } \\
\text { PEGR = Valor Adicionado / } \mathrm{N}^{\circ} \text { médio Empregados }\end{array}$ \\
\hline $\begin{array}{l}\text { Potencial do } \\
\text { Patrimônio Líquido } \\
\text { para gerar riqueza } \\
\text { (PPLGR) }\end{array}$ & $\begin{array}{l}\text { Indica o potencial do Patrimônio Líquido para geração de riquezas da empresa. Na } \\
\text { forma de índice, mensura quanto cada real investido de capital próprio contribuiu para } \\
\text { geração do Valor Adicionado que será distribuído pela empresa. } \\
\text { PPLGR = (Valor Adicionado / PL médio) x } 100\end{array}$ \\
\hline $\begin{array}{l}\text { Indicadores de } \\
\text { distribuição da } \\
\text { riqueza }\end{array}$ & $\begin{array}{l}\text { Evidenciam como e a quem a empresa está destinando a riqueza criada. Esse indicador } \\
\text { também se obtém a comparação da DVA com ela mesma. }\end{array}$ \\
\hline $\begin{array}{l}\text { Participação dos } \\
\text { empregados no Valor } \\
\text { Adicionado (PEVA) }\end{array}$ & $\begin{array}{l}\text { Evidencia o quanto de Valor Adicionado a empresa está destinando à sua força de } \\
\text { trabalho. } \\
\qquad \mathrm{PEVA}=(\text { Pessoal / Valor adicionado }) \times 100\end{array}$ \\
\hline
\end{tabular}




\begin{tabular}{|l|l|}
\hline $\begin{array}{l}\text { Participação per } \\
\text { capita dos } \\
\text { empregados no Valor } \\
\begin{array}{l}\text { Adicionado (PEVA } \\
\text { per capita) }\end{array}\end{array}$ & $\begin{array}{l}\text { Demonstra o quanto de Valor Adicionado a empresa está distribuindo aos seus } \\
\text { empregados, individualmente. O valor encontrado é uma estimativa dos gastos médio } \\
\text { que a empresa tem por empregado. } \\
\text { PEVA per capita = Valor Adicionado Distribuído aos Empregados / } \\
\text { Empregados }\end{array}$ \\
\hline $\begin{array}{l}\text { Participação do } \\
\text { governo no Valor } \\
\text { Adicionado (PGVA) }\end{array}$ & $\begin{array}{l}\text { Mostra a contribuição da empresa à sociedade por meio do pagamento de tributos. } \\
\text { Esse indicador destaca o quanto a empresa participa na realização de obras, } \\
\text { manutenção de atividades sociais e outros, que são realizados com arrendação fiscal. } \\
\text { PGVA = governo / Valor Adicionado x 100 }\end{array}$ \\
\hline $\begin{array}{l}\text { Participação de } \\
\text { terceiros no Valor } \\
\text { Adicionado (PTVA) }\end{array}$ & $\begin{array}{l}\text { Demonstra o quanto da riqueza gerada pela empresa está sendo destinado aos } \\
\text { financiadores, sob a forma de juros e aluguéis e, também, de royalties, franquias e } \\
\text { direitos autorais. } \\
\text { PTVA = Remuneração de Capitais de Terceiros / Valor Adicionado x 100 }\end{array}$ \\
\hline $\begin{array}{l}\text { Participação dos } \\
\text { capitais próprios no } \\
\text { Valor Adicionado } \\
\text { (PCPVA) }\end{array}$ & $\begin{array}{l}\text { Mostra o quanto da riqueza gerada pela empresa está sendo destinado aos acionistas } \\
\text { em forma de dividendos e juros sobre os capitais próprios. Inclui também o valor } \\
\text { relativos ao lucro do exercício que foi destinado às reservas. } \\
\text { PCPVA = Remuneração dos Capitais Próprios /Valor Adicionado x 100 }\end{array}$ \\
\hline $\begin{array}{l}\text { Grau de retenção do } \\
\text { Valor Adicionado } \\
\text { (GRVA) }\end{array}$ & $\begin{array}{l}\text { Consiste apenas avaliar quando do Valor Adicionado ficou retido na empresa de } \\
\text { reservas e /ou prejuízos acumulados. } \\
\text { GRVA = Lucros Retidos/ Prejuízos Exercícios / Valor Adicionado x 100 }\end{array}$ \\
\hline
\end{tabular}

Fonte: Adaptado de De Luca (2009, p.132, 133, 134, 135)

Além dos indicadores do Quadro 1, a DVA é demonstrada por meio de índices de geração de valor adicionado, o que pode ser observado no Quadro 2.

Quadro 2 - Indicadores geração e distribuição do valor adicionado

\begin{tabular}{|c|c|c|}
\hline \multicolumn{3}{|c|}{ Índices de geração de Valor Adicionado } \\
\hline $\begin{array}{l}\text { Grau de Contribuição para } \\
\text { Riqueza de Terceiros. }\end{array}$ & $\begin{array}{l}\text { GCRT = } \\
(\text { CRT/Receita) X } 100\end{array}$ & $\begin{array}{l}\text { Serve para indicar o quanto da Receita Total a } \\
\text { empresa destina a pagamento de terceiros. }\end{array}$ \\
\hline $\begin{array}{l}\text { Grau de Valor Adicionado } \\
\text { Bruto em relação à Receita. }\end{array}$ & $\begin{array}{l}\text { GVAB = } \\
\text { VAB/Receita }\end{array}$ & $\begin{array}{l}\text { Mede o quanto da Receita Total a empresa consegue } \\
\text { agregar como Valor Adicionado Bruto. }\end{array}$ \\
\hline $\begin{array}{l}\text { Grau de Valor Adicionado Total } \\
\text { em relação à Receita. }\end{array}$ & $\begin{array}{l}\text { GVAT = } \\
\text { (VAT/receita) X } 100\end{array}$ & $\begin{array}{l}\text { Mede o quanto da Receita Total a empresa consegue } \\
\text { agregar como Valor Adicionado Bruto }\end{array}$ \\
\hline $\begin{array}{l}\text { GRRT = Grau de Recebimento } \\
\text { de Riqueza por Transferência. }\end{array}$ & $\begin{array}{l}\text { GRRT }=(\text { RRT/VAT }) \\
\text { X } 100\end{array}$ & $\begin{array}{l}\text { Mede o quanto do Valor Adicionado Total a } \\
\text { Distribuir é proveniente de recebimento de terceiros. }\end{array}$ \\
\hline $\begin{array}{l}\text { GPRP = Grau de Produção de } \\
\text { Riqueza Própria. }\end{array}$ & $\begin{array}{l}\text { GPRP }=(\text { PRP/VAT }) \\
\text { X } 100\end{array}$ & $\begin{array}{l}\text { Mede o quanto do Valor Adicionado Total a } \\
\text { Distribuir é proveniente da produção da empresa. }\end{array}$ \\
\hline \multicolumn{3}{|c|}{ Índices de distribuição do Valor Adicionado } \\
\hline $\begin{array}{l}\text { Percentual de Distribuição do } \\
\text { Valor Adicionado ao Governo. }\end{array}$ & $\begin{array}{l}\text { PDVAG) = } \\
(\text { VAG/VATD) X } 100\end{array}$ & $\begin{array}{l}\text { Avalia o percentual do Valor Adicionado Total a } \\
\text { Distribuir que foi destinado ao Governo }\end{array}$ \\
\hline $\begin{array}{l}\text { Percentual de Distribuição do } \\
\text { Valor Adicionado ao Acionista. }\end{array}$ & $\begin{array}{l}\text { PDVA })= \\
\text { VAA/VATD X } 100\end{array}$ & $\begin{array}{l}\text { Avalia o percentual do Valor Adicionado Total a } \\
\text { Distribuir que foi destinado aos Acionistas }\end{array}$ \\
\hline $\begin{array}{l}\text { Percentual de Distribuição do } \\
\text { Valor Adicionado a Empregados }\end{array}$ & $\begin{array}{l}\text { PDVAE) } \\
=\text { VAE/VATD }\end{array}$ & $\begin{array}{l}\text { Avalia o percentual do Valor Adicionado Total a } \\
\text { Distribuir que foi destinado aos empregados. }\end{array}$ \\
\hline $\begin{array}{l}\text { Percentual de Retenção do } \\
\text { Valor Adicionado }\end{array}$ & $\begin{array}{l}\text { PRVA }=(\text { Retenção/ } \\
\text { VATD) X } 100\end{array}$ & $\begin{array}{l}\text { Mede o percentual do Valor Adicionado Total a } \\
\text { Distribuir que foi retido pela empresa }\end{array}$ \\
\hline $\begin{array}{l}\text { Percentual de Distribuição do } \\
\text { Valor Adicionado as } \\
\text { Instituições Financeiras }\end{array}$ & $\begin{array}{l}\text { PDVAIF }=(\text { VAIF/ } \\
\text { VATD }) \times 100\end{array}$ & $\begin{array}{l}\text { Avalia o percentual do Valor Adicionado Total a } \\
\text { Distribuir que foi destinado as Instituições } \\
\text { Financeiras. }\end{array}$ \\
\hline
\end{tabular}

Fonte: FIPECAFI, 2013.

Quadro 3 - Indicadores Análise setorial

\begin{tabular}{|l|l|l|l|}
\hline Indicadores & FÓRMULA & Onde & Interpretação:
\end{tabular}




\begin{tabular}{|l|l|l|l|}
\hline $\begin{array}{l}\text { Taxa de Contribuição } \\
\text { do PL (TCPL) }\end{array}$ & $\begin{array}{l}\text { TCPL= (VATD/PL) } \\
\text { X 100 }\end{array}$ & $\begin{array}{l}\text { VATD: Valor adicionado } \\
\text { total a distribuir. PL: Puanto da riqueza gerada (\%), } \\
\text { Patrimônio Líquido }\end{array}$ & $\begin{array}{l}\text { luém do capital próprio. Quanto } \\
\text { maior, melhor. }\end{array}$ \\
\hline $\begin{array}{l}\text { Taxa de Geração de } \\
\text { Riqueza }- \text { TGR }\end{array}$ & $\begin{array}{l}\text { TGR = (VATD/AT) } \\
\text { X 100 }\end{array}$ & $\begin{array}{l}\text { VATD: Valor Adicionado } \\
\text { AT: Ativo Total }\end{array}$ & $\begin{array}{l}\text { Determina a capacidade do ativo } \\
\text { de gerar riqueza. Quanto maior, } \\
\text { melhor. }\end{array}$ \\
\hline $\begin{array}{l}\text { Taxa de Retenção da } \\
\text { Riqueza }- \text { TRR }\end{array}$ & $\begin{array}{l}\text { TRR }=(\text { LL/VATD) } \\
\text { X 100 }\end{array}$ & $\begin{array}{l}\text { LL: Lucro Líquido } \\
\text { VATD: Valor Adicionado }\end{array}$ & $\begin{array}{l}\text { Mensura o ganho econômico da } \\
\text { riqueza (\%). Quanto maior, } \\
\text { melhor. }\end{array}$ \\
\hline
\end{tabular}

Fonte: FIPECAFI, 2013.

Para elucidar a estrutura da DVA foi utilizado os modelos apresentados na Comissão Valores Mobiliário (CVM) No 557 de 12 de novembro de 2008 e no CPC 09. Ainda segundo o CPC 09, esses modelos (Figura 1, 2 e 3) devem ser entendidos como indicativos para um maior detalhamento, em nome da maior transparência.

Sobre a estrutura da DVA o CPC 09 menciona que existem três modelos: Modelo I deve ser utilizado pelas prestadoras de serviço e empresas mercantis (comercias e industriais), sendo assim, é admissível para as entidades em geral.

Figura 1 - Modelo I: Demonstração do Valor Adicionado- Empresas em geral

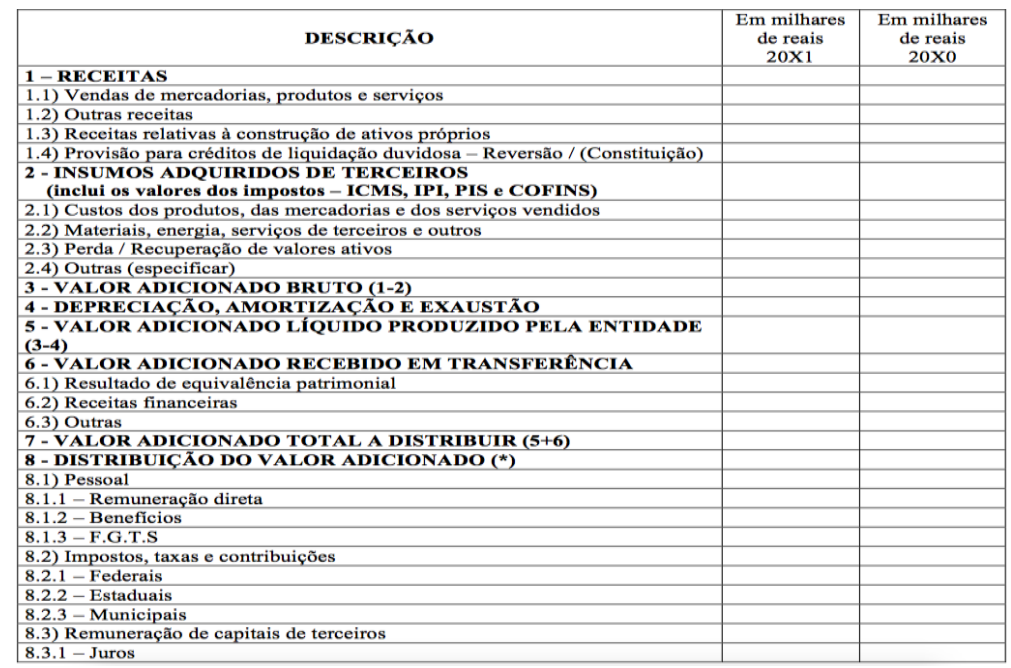

Fonte: Deliberação CVM 557, de 12/11/2008. p. 15 e16.

(*) O total do item 8 deve ser exatamente igual ao item 7.

O Modelo II (Figura 2) é utilizado por atividades específicas tais como atividades de intermediação financeira (instituições financeiras bancárias). Sobre essa demonstração, De Luca (2009, p.57) informa que:

As instituições financeiras têm os juros como remuneração de seus serviços e produtos, constituindo-se, portanto, em suas receitas principais, ao contrário do que ocorre com as demais empresas, que os têm como valores recebidos em transferência. Igualmente, os juros pagos no desenvolvimento de suas atividades 
principais são tratados como redutores da receita, de forma a identificar o montante dos recursos gerados por outras companhias, e não como distribuição do Valor Adicionado.

O Modelo III (Figura 3) é utilizado pelas seguradoras. Sua distribuição informa

As receitas destacadas são aquelas com operações de seguro e previdência complementar. As primeiras incluem venda de apólices e operações de cosseguros aceitas, líquidas dos prêmios restituídos ou cancelados e de retrocessão e as oriundas das operações de recuperação de sinistros com salvados e ressarcimento. As receitas de previdência complementar segregarão o montante de vendas de planos de previdência. Foi prevista, ainda, linha especial para registro de atividade de gestão, a qual se dominou Rendas com taxas de gestão (DE LUCA, 2009, p. 61).

Figura 2 - Modelo II: Demonstração do Valor Adicionado - Instituições Financeiras Bancárias

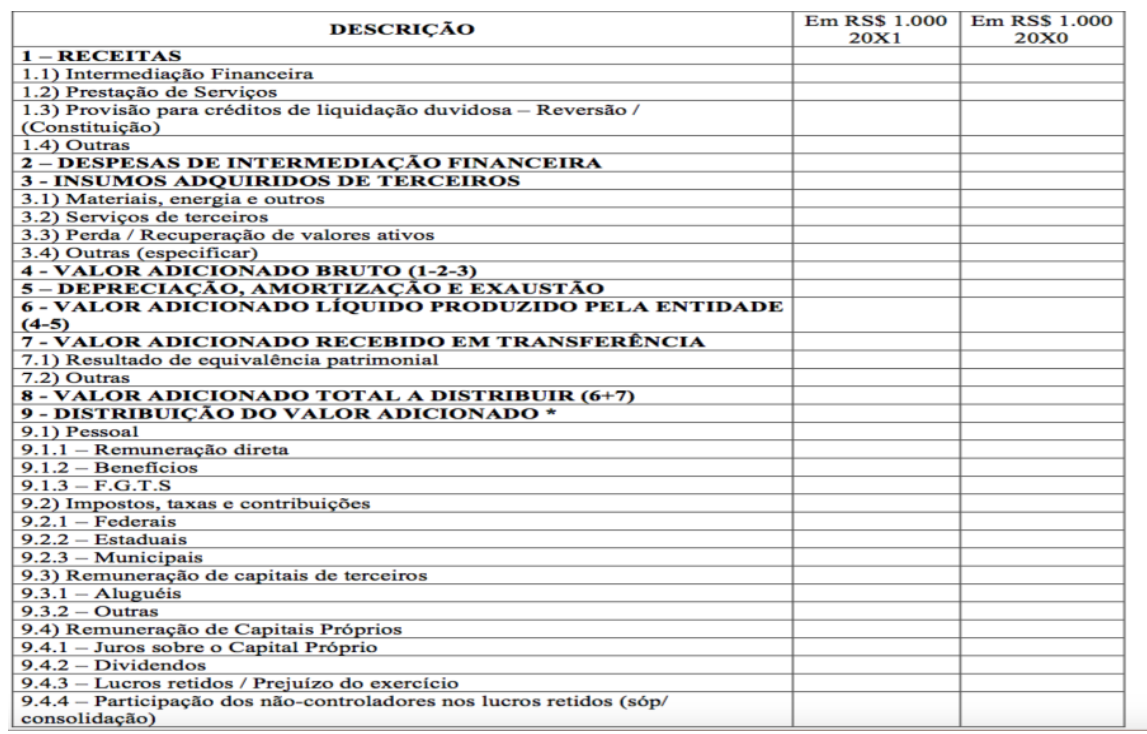

Fonte: Deliberação CVM 557, de 12/11/2008. p. 17-18

(*) $O$ total do item 9 deve ser exatamente igual ao item 8.

Figura 3 - Modelo III: Demonstração do Valor Adicionado - SEGURADORAS

(Modelo sugerido pela Superintendência de Seguros Privados - Susep) 


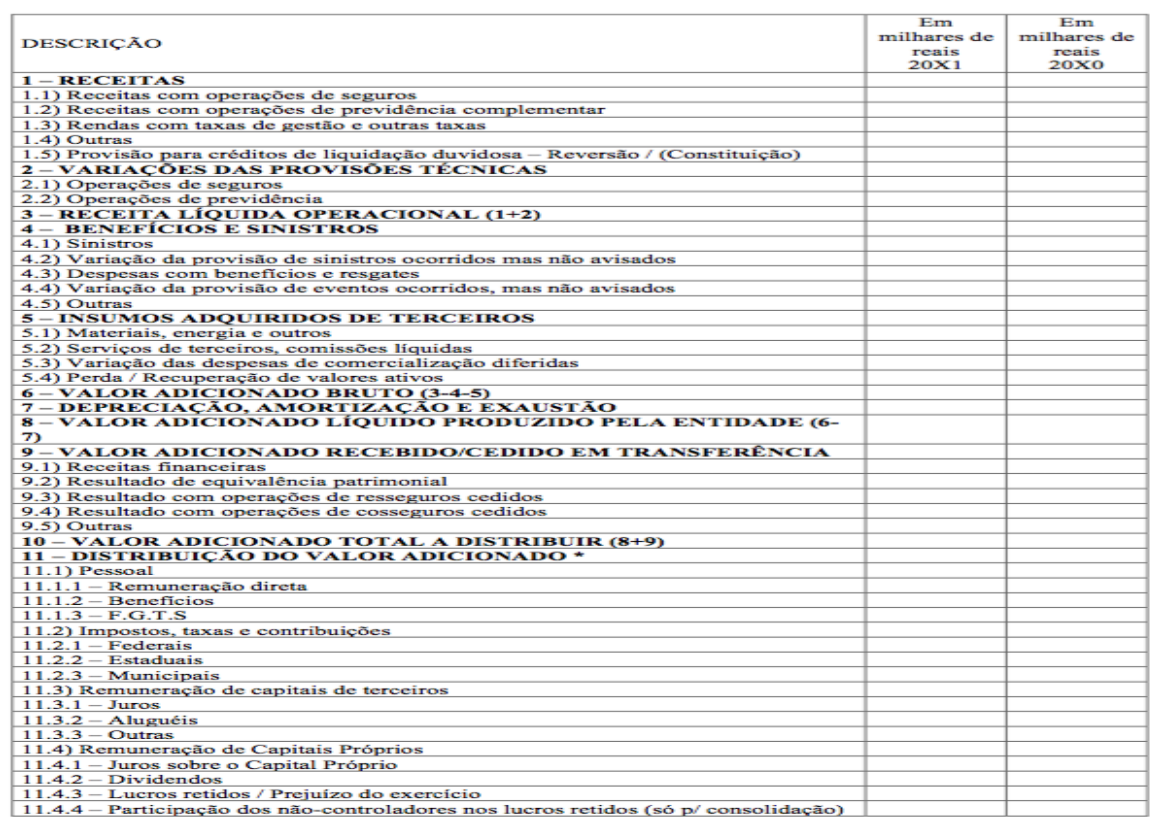

Fonte: Deliberação CVM 557, de 12/11/2008. P. 19-20

(*) $O$ total do item 11 deve ser exatamente igual ao item 10.

\section{METODOLOGIA DE PESQUISA}

A pesquisa científica prevê a articulação formal do método com o pensamento reflexivo que se debruça sobre a realidade na perspectiva de desvendar verdades provisórias e parciais (MARCONI; LAKATOS, 2001). Nesse sentido, a presente investigação assume caráter descritivo, haja vista o "objetivo primordial a descrição das características de determinada população ou fenômeno ou, então, o estabelecimento de relações entre variáveis". (GIL, 1996, p.46).

Realizou-se um levantamento documental em 2015.2 nas empresas cearenses de alimentos, especificadamente na parte trigo, refino de óleo, gorduras, margarinas e cremes vegetais, bolos, torradas e misturas dentro outros produtos, que estão dentre as listadas na BM\&FBovespa. Esta representa uma companhia que administra mercados organizados de títulos, valores mobiliários e contratos derivativos, prestando serviços de registro, compensação e liquidação, atuando, principalmente, como contraparte central garantidora da liquidação financeira das operações realizadas em seus ambientes.

Para a coleta e análise de dados, utilizou-se dados das empresas cearenses, M. Dias Branco S. A. Ind.Com. de Alimentos e J Macedo S. A, a partir das demonstrações financeiras, consultadas na base de dados da BM\&FBovespa no período de 2008 a 2014, em que esses anos foram marcados por uma crise econômica que iniciou nos Estados Unidos e a qual teve 
um grande impacto no Brasil com relação a cessão de créditos para as empresas e os consumidos por falta de investimentos.

A empresa M. Dias Branco S. A. Ind.Com. de Alimentos é uma empresa de capital aberto que mantém seu foco na fabricação, venda e distribuição de biscoitos, bolachas e massas. Iniciou suas atividades em 1936 na cidade Fortaleza e atualmente sua fábrica se localiza no município de Eusébio.

A segunda empresa estudada, foi a J Macêdo, fundada 1939, em Fortaleza, no Ceará oferecendo produtos diversificados, que abrangiam desde a manteiga mineira até a madeira do Estado do Pará. Atualmente, caracteriza-se por ser líder de mercado nos segmentos de trigo domésticos e de mistura de bolos. É considerada, a terceira maior empresa nacional no segmento de massas alimentícias e a fabricante líder em vendas na capital de São Paulo.

A técnica de análise de dados, é feita com base nos indicadores de geração de valor adicionado, indicadores de distribuição do valor adicionado e na análise dos indicadores setorial. As informações foram retiradas da DVA, do Patrimônio Líquido, da Demonstração Resultado do Período (receitas) e do Ativo Total compreendendo os anos de 2008 a 2014.

\section{RESULTADOS}

Nesta seção, expõem-se os gráficos das empresas estudadas de maneira individual com a finalidade de permitir melhor análise entre valor adicionado e patrimônio líquido, bem como vendas e ativo total.

\section{Empresa 1 - M. Dias Branco}

Segue abaixo o Gráfico 1 com a análise dos Índices de Geração de Valor Adicionado. 
Gráfico 1 - Índices de Geração de Valor Adicionado

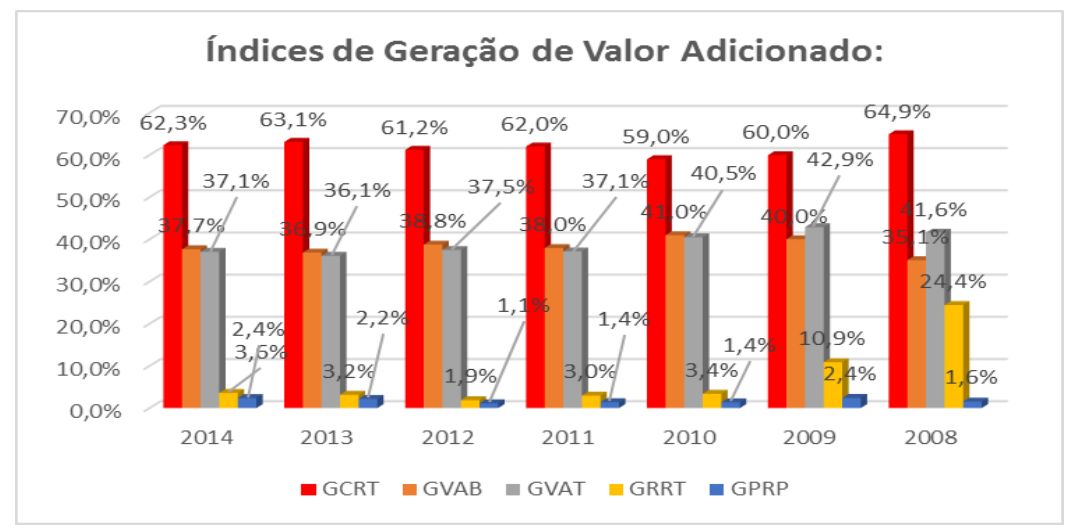

Fonte: Elaborada pelas autoras com base nos dados da pesquisa (2015).

Por meio do indicador GCRT (Grau de Contribuição para Riqueza de Terceiros), observa-se um aumento da Receita Total da empresa destinada ao pagamento de terceiros nos anos de 2008 a 2009. No ano de 2010 houve uma diminuição do percentual da receita destinada ao pagamento de terceiros. E nos anos de 2011 a 2014 aconteceu um aumento do percentual da receita Total da empresa destinada ao pagamento de terceiros.

O do indicador GVAB (Grau de Valor Adicionado Bruto em Relação à Receita), por sua vez, indica que houve aumento do quanto da Receita Total agrega ao Valor Adicionado Bruto nos anos de 2008 a 2010. E, nos anos de 2011 a 2014, acontece um aumento e diminuição do quanto da Receita Total agregou como Valor Adicionado Bruto.

Por meio do indicador GVAT (Grau de Valor Adicionado Total em Relação à Receita), observa-se um aumento do quanto da Receita Total a empresa consegue agregar como Valor do Adicionado Bruto nos anos 2008 a 2009. Enquanto nos anos de diminuição e aumento nos anos 2010 a 2014 desse valor.

No indicador Grau de Recebimento de Riqueza por Transferência, verifica-se que nos anos de 2008 e 2009 ocorreu um aumento do quanto do Valor Adicionado Total a Distribuir é proveniente de recebimento de terceiros. Nos anos de 2010 a 2014, ocorreram aumentos e diminuições do quanto do Valor Adicionado Total a distribuir é proveniente de recebimentos de terceiros.

Nos anos de 2008 a 2009 ocorreu aumento do quanto do Valor Adicionado Total a Distribuir é proveniente da produção da empresa. Nos anos entre 2010 a 2014 comparando com os anos mencionados anteriormente ocorreu um aumento e diminuição do Valor Adicionado Total a Distribuir é resultante da produção da empresa. 
Após exame dos índices de geração de valor, analisa-se o valor distribuído por meio dos indicadores de distribuição de valor adicionado evidenciados no Gráfico 2.

Gráfico 2- Índices de Distribuição de Valor Adicionado

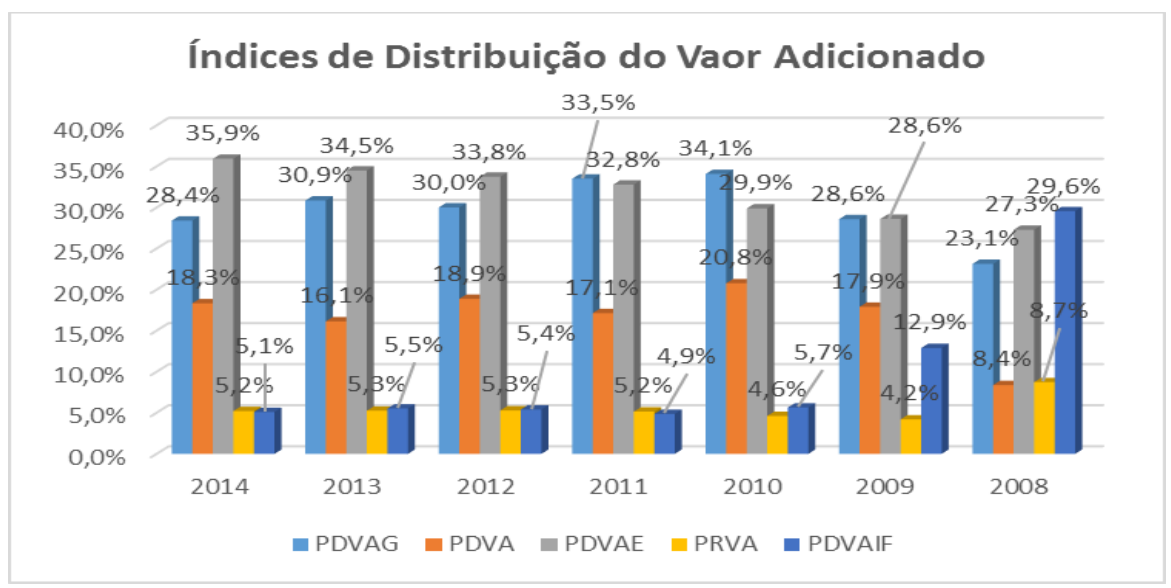

Fonte: Elaborado pela autora com base nos dados da pesquisa (2015).

Ao aplicar o Percentual de Distribuição do Valor Adicionado ao Governo (PDVAG), nos anos de 2008 a 2010 ocorreu um aumento no percentual do valor adicionado total a distribuir que foi destinado ao Governo. Nos anos 2011 a 2014 teve uma redução do percentual do valor adicionado total a distribuir que foi distribuído ao governo.

Utilizados o Percentual de Distribuição do Valor Adicionado ao Acionista (PDVA), observa-se que ocorreu um aumento do valor adicionado total a distribuir que foi aos acionistas. E nos anos de 2011 a 2014 ocorreu um aumentos e diminuições do percentual do valor adicionado total a distribuir que foi destinado aos acionistas.

Utilizando-se o Percentual de Distribuição do Valor Adicionado a Empregados (PDAE), percebe-se um aumento nos anos de 2008 a 2014 do percentual valor adicionado total a distribuir que se destina aos empregados.

Por meio do indicador Percentual de Retenção do Valor Adicionado (PRVA), observase uma diminuição do percentual do valor adicionado total a distribuir que foi retido pela empresa nos anos de 2008 a 2010. Obteve, ainda, um pequeno aumento de 2011 a 2013 e uma diminuição em 2014

Com a utilização do indicador Percentual de Distribuição do Valor Adicionado as Instituições Financeiras, observa-se uma significativa diminuição do percentual do valor adicionado total a distribuir que foi destinado as Instituições Financeiras nos 2008 a 2014. 
Por fim, com o intuito de identificar a atratividade e o risco do setor em que a entidade atua evidencia-se os indicadores de análise setorial no Gráfico 3.

Gráfico 3: Indicadores de Análise Setorial

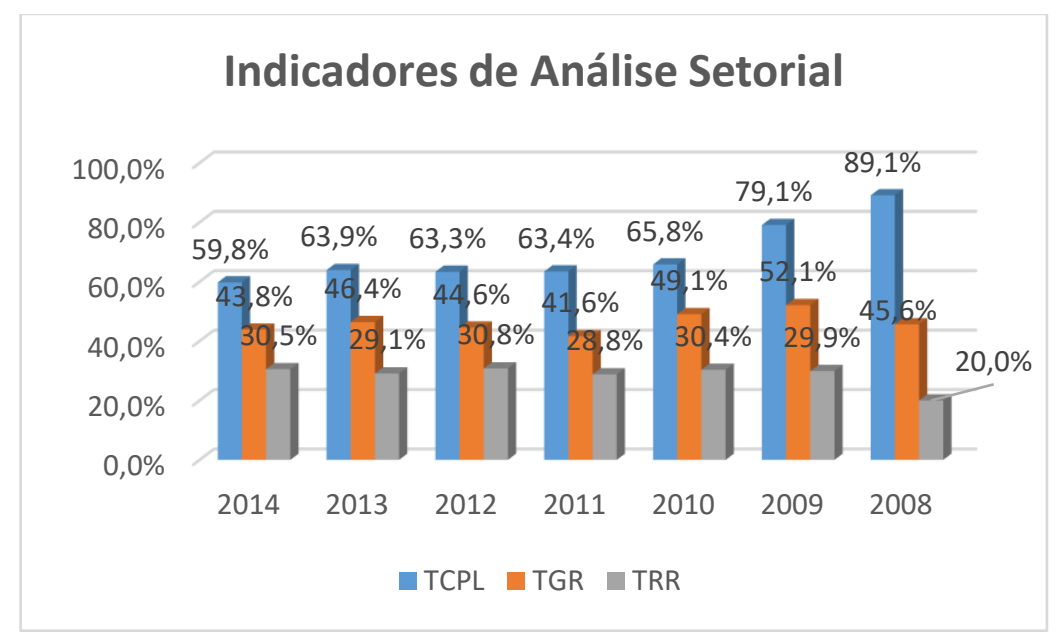

Fonte: Elaborado pela autora com base nos dados da pesquisa (2015).

Aplicando a Taxa de Contribuição do Patrimônio Líquido, observa-se que a porcentagem que provem da Capital Próprio está diminuindo durante os anos de 2008 a 2014.

Aplicando a Taxa de Geração de Riqueza (TGR), verifica-se que ocorreu um aumento nos anos de 2008 a 2011 da porcentagem da capacidade do ativo gerar riqueza. Nos anos de 2010 a 2014 houve uma diminuição do percentual da capacidade do ativo de gerar riqueza.

Através da Taxa de Retenção da Riqueza (TRR), mensura-se que nos anos de 2008 a 2010 ocorreu um aumento do ganho econômico da riqueza. E nos anos seguintes de 2011 a 2014 ocorreu um aumento e uma redução do percentual de ganho econômico da riqueza. Ressalta-se quanto maior melhor.

\section{Empresa 2 - J. Macedo S. A.}

O Gráfico 4 dispõe informações sobre os Índices de geração de valor Adicionado.

Por meio do indicador GCRT (Grau de Contribuição para Riqueza de Terceiros), observa-se um aumento da Receita Total da empresa destinada ao pagamento de terceiros nos anos de 2008 e 2011. No ano de 2012 a 2014 houve uma redução e aumento do percentual da receita destinada ao pagamento de terceiros. 
Gráfico 4: Indicadores de geração de Valor Adicionado

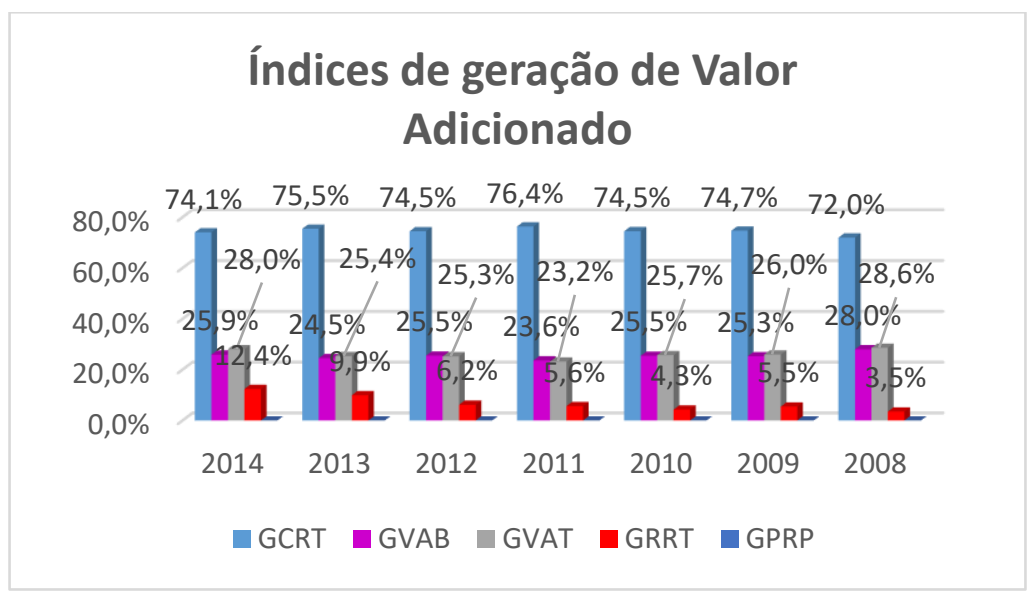

Fonte: Elaborado pela autora com base nos dados da pesquisa (2015).

O indicador GVAB (Grau de Valor Adicionado Bruto em Relação à Receita), por sua vez indica que houve aumento do quanto da Receita Total agrega ao Valor Adicionado Bruto nos anos de 2008 a 2009. E nos anos de 2010 a 2014 acontece um aumento e diminuição do quanto da Receita Total agregou como Valor Adicionado Bruto.

Por meio do indicador GVAT (Grau de Valor Adicionado Total em Relação à Receita), observa-se uma redução significativa do quando da Receita Total a empresa consegui agregar como Valor do Adicionado Bruto nos anos 2008 a 2011. Enquanto nos anos seguintes ocorreu aumento dessa porcentagem.

No indicador Grau de Recebimento de Riqueza por Transferência, verifica-se um aumento da porcentagem do quanto do Valor Adicionado Total a Distribuir é proveniente de recebimento de terceiros nos anos de 2008 a 2014.

Nos anos de 2008 a 2014 não se obteve porcentagem do quanto do Valor Adicionado Total a Distribuir é proveniente da produção da empresa, pois não teve Receitas referentes à Construção de Ativos Próprios. 
Gráfico 5: Índices de distribuição do Valor Adicionado.

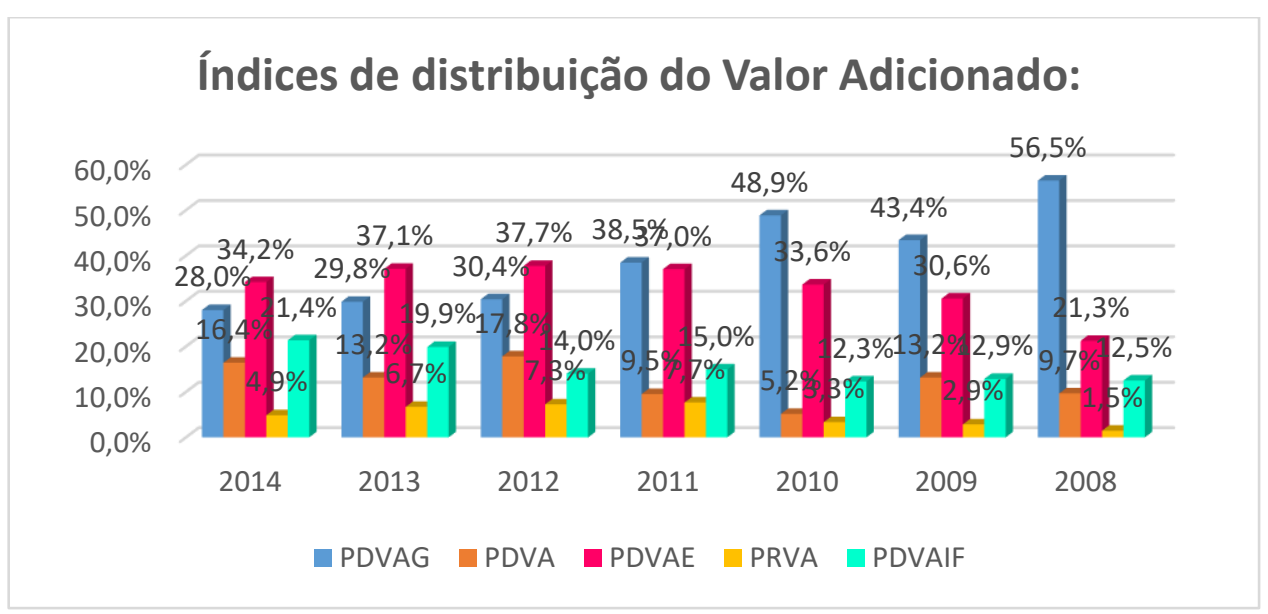

Fonte: Elaborado pela autora com base nos dados da pesquisa (2015).

Aplicando o Percentual de Distribuição do Valor Adicionado ao Governo (PDVAG), nos anos de 2008 a 2009 ocorreu uma diminuição no percentual do valor adicionado total a distribuir que foi destinado ao Governo. No ano de 2010 ocorreu crescimento do percentual, mas nos seguintes de 2011 a 2014 verifica-se uma redução do percentual do valor adicionado total a distribuir que foi distribuído ao governo.

Utilizados o Percentual de Distribuição do Valor Adicionado ao Acionista (PDVA), observa-se que ocorreu um aumento do valor adicionado total a distribuir que foi aos acionistas nos anos de 2008 e 2009. E nos anos de 2010 a 2014 verifica-se uma redução e um aumento significativo do percentual do valor adicionado total a distribuir que foi destinado aos acionistas.

Utilizando-se o Percentual de Distribuição do Valor Adicionado a Empregados (PDAE), percebe-se um aumento nos anos de 2008 a 2013 do percentual valor adicionado total a distribuir que se destina aos empregados. E no ano 2014 ocorreu uma queda desse percentual.

Através do indicador Percentual de Retenção do Valor Adicionado (PRVA), observa-se um crescimento do percentual do valor adicionado total a distribuir que foi retido pela empresa nos anos de 2008 a 2012. E nos anos 2013 e 2014 obteve uma leve diminuição desse percentual.

Com a utilização do indicar Percentual de Distribuição do Valor Adicionado as Instituições Financeiras, observa-se um aumento do percentual do valor adicionado total a distribuir que foi destinado as Instituições Financeiras no 2014 para 2013. Uma pequena redução desse percentual no ano 2010 e nos de 2011 a 2014 ocorreu um aumento significativo desse percentual. 
Gráfico 6: Indicadores de Análise Setorial

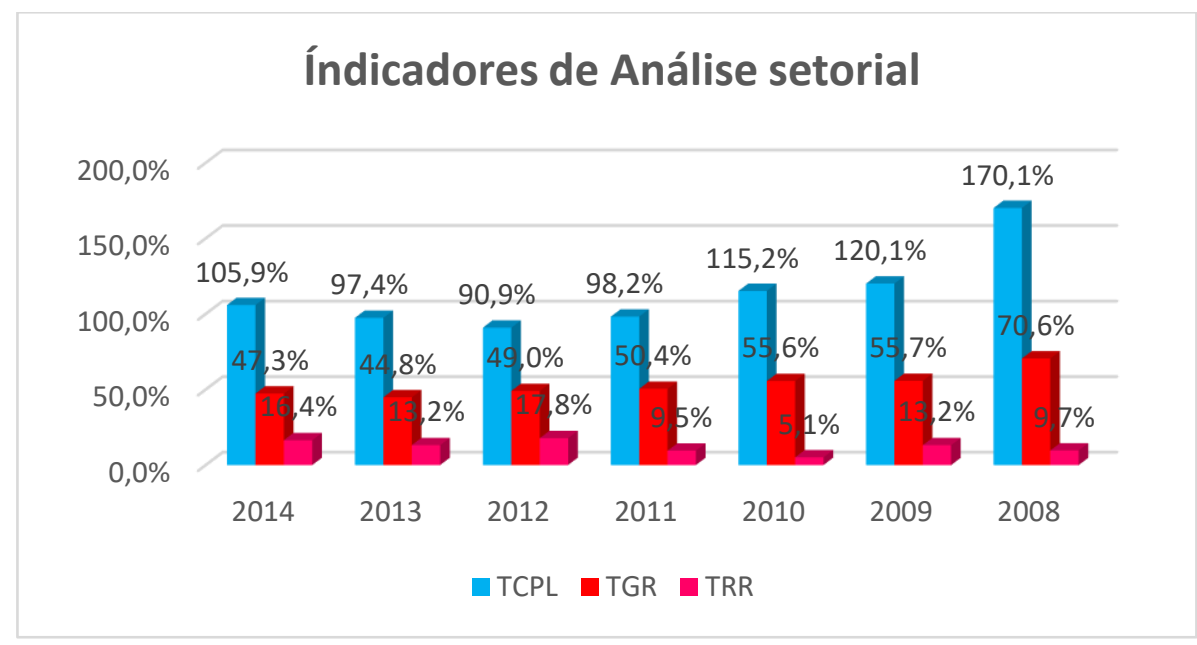

Fonte: Elaborado pela autora com base nos dados da pesquisa (2015).

Aplicando a Taxa de Contribuição do Patrimônio Líquido, observa-se uma considerável redução porcentagem que provem da Capital Próprio está diminuindo durante os anos de 2008 a 2012. Nos anos de 2013 e 2014 ocorreu um aumento significativo do percentual.

Aplicando a Taxa de Geração de Riqueza (TGR), verifica-se que ocorreu uma redução considerável nos anos de 2008 a 2013 da porcentagem da capacidade do ativo gerar riqueza. No ano de 2014 ocorreu um pequeno aumento do percentual da capacidade do ativo de gerar riqueza.

Através da Taxa de Retenção da Riqueza (TRR), mensura-se que nos anos de 2008 a 2009 ocorreu um aumento do ganho econômico da riqueza. E no ano de 2010 reduziu essa porcentagem, mas se recuperou com crescimento nos anos de 2011 e 2012 e reduziu em 2013 e aumentou no ano seguinte. Ressalta-se quanto maior melhor.

\section{Empresa 1 - M dias Branco}

O Quadro 4 e gráfico 7 indicam a análise Valor Adicionado x Patrimônio Líquido x Vendas e Ativo Total.

Quadro 4 - Dados coletados do site da BM\&FBovespa.

\begin{tabular}{|c|c|c|c|c|c|r|r|}
\hline & $\mathbf{2 0 0 8}$ & $\mathbf{2 0 0 9}$ & $\mathbf{2 0 1 0}$ & $\mathbf{2 0 1 1}$ & $\mathbf{2 0 1 2}$ & \multicolumn{1}{c|}{$\mathbf{2 0 1 3}$} & \multicolumn{2}{c|}{014} \\
\hline & & & & & & $\mathrm{R} \$$ & $\mathrm{R} \$$ \\
$\mathrm{AT}$ & $\mathrm{R} \$ 4.478 .247$ & $\mathrm{R} \$ 3.884 .901$ & $\mathrm{R} \$ 3.426 .892$ & $\mathrm{R} \$ 3.058 .156$ & $\mathrm{R} \$ 2.361 .609$ & 2.258 .006 & 2.347 .792 \\
\hline & & & & & & $\mathrm{R} \$$ & $\mathrm{R} \$$ \\
$\mathrm{PL}$ & $\mathrm{R} \$ 3.285 .643$ & $\mathrm{R} \$ 2.820 .095$ & $\mathrm{R} \$ 2.410 .618$ & $\mathrm{R} \$ 2.005 .773$ & $\mathrm{R} \$ 1.760 .517$ & 1.487 .297 & 1.202 .896 \\
\hline $\mathrm{RL}$ & $\mathrm{R} \$ 4.579 .890$ & $\mathrm{R} \$ 4.311 .638$ & $\mathrm{R} \$ 3.545 .152$ & $\mathrm{R} \$ 2.911 .033$ & $\mathrm{R} \$ 2.444 .000$ & $\mathrm{R} \$$ & $\mathrm{R} \$$ \\
\hline
\end{tabular}




\begin{tabular}{|l|l|l|l|l|r|r|r|} 
& & & & & 2.347 .898 & 2.192 .571 \\
\hline VTDA & $\mathrm{R} \$ 1.963 .276$ & $\mathrm{R} \$ 1.802 .464$ & $\mathrm{R} \$ 1.526 .792$ & $\mathrm{R} \$ 1.272 .590$ & $\mathrm{R} \$ 1.158 .601$ & 1.176 .399 & 1.071 .740 \\
\hline
\end{tabular}

Fonte: Pesquisa documental (BOVESPA, 2015).

Aplicado a formula do indicador (TCPL), ocorreu uma redução no valor adicionado a distribuir nos anos 2008 a 2014, consequentemente reduziu o quanto da riqueza gerada provém de capitais próprios.

Gráfico 7: Análise do VTDA x PL x Vendas x Ativo Total

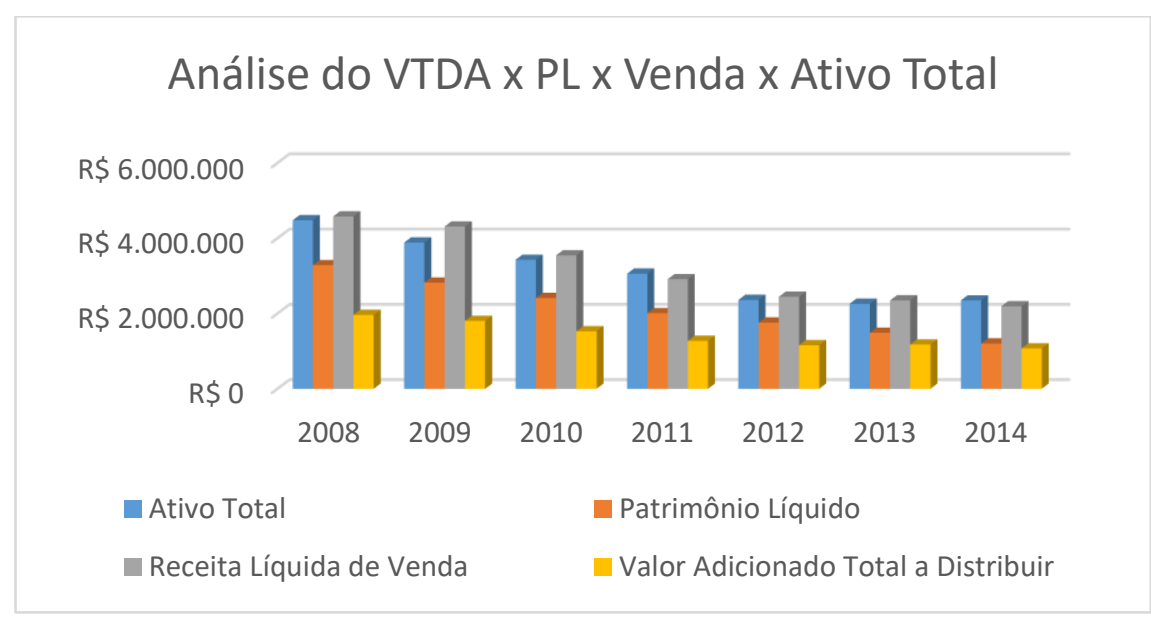

Fonte: Elaborado pela autora com base nos dados da pesquisa (2015).

Como nos anos de 2008 a 2014, o valor adicionado a distribuir e ativo total reduziu então diminui a capacidade do ativo de gerada de riqueza.

Como a Venda diminuiu e o valor adicionado total adicionado diminuíram então o ganho econômico da riqueza diminuiu consequentemente.

\section{Empresa 2 - J Macêdo}

O Quadro 5 e Gráfico 8 indicam a análise VA x PL x Vendas e Ativo Total. Quadro 5 - Dados coletados do site da BM\&FBovespa.

\begin{tabular}{|c|r|r|r|r|r|r|r|}
\hline & $\mathbf{2 0 0 8}$ & $\mathbf{2 0 0 9}$ & $\mathbf{2 0 1 0}$ & $\mathbf{2 0 1 1}$ & $\mathbf{2 0 1 2}$ & $\mathbf{2 0 1 3}$ & $\mathbf{2 0 1 4}$ \\
\hline $\mathrm{AT}$ & $\mathrm{R} \$ 1.022 .591$ & $\mathrm{R} \$ 865.258$ & $\mathrm{R} \$ 704.981$ & $\mathrm{R} \$ 634.684$ & $\mathrm{R} \$ 614.414$ & 632.105 & $\mathrm{R} \$ 606.735$ \\
\hline $\mathrm{PL}$ & $\mathrm{R} \$ 456.863$ & $\mathrm{R} \$ 398.253$ & $\mathrm{R} \$ 380.186$ & $\mathrm{R} \$ 325.899$ & $\mathrm{R} \$ 296.467$ & 293.303 & $\mathrm{R} \$ 251.718$ \\
\hline $\mathrm{RL}$ & $\mathrm{R} \$ 1.508 .942$ & $\mathrm{R} \$ 1.354 .911$ & $\mathrm{R} \$ 1.193 .048$ & 1.226 .979 & 1.179 .902 & 1.180 .208 & 1.271 .383 \\
\hline & & & & $\mathrm{R} \$$ & $\mathrm{R} \$$ & $\mathrm{R} \$$ & \\
$\mathrm{VTDA}$ & $\mathrm{R} \$ 483.877$ & $\mathrm{R} \$ 388.031$ & $\mathrm{R} \$ 345.570$ & $\mathrm{R} \$ 320.081$ & $\mathrm{R} \$ 341.602$ & 352.249 & $\mathrm{R} \$ 428.295$ \\
\hline
\end{tabular}

Fonte: Pesquisa documental (BOVESPA, 2015). 
Como ocorreu um aumento da VATD e uma diminuição do PL nos anos 2008 a 2014 então quanto da riqueza gerada provém do capital de terceiros.

Gráfico 8: Análise do VTDA x PL x Vendas x Ativo Total

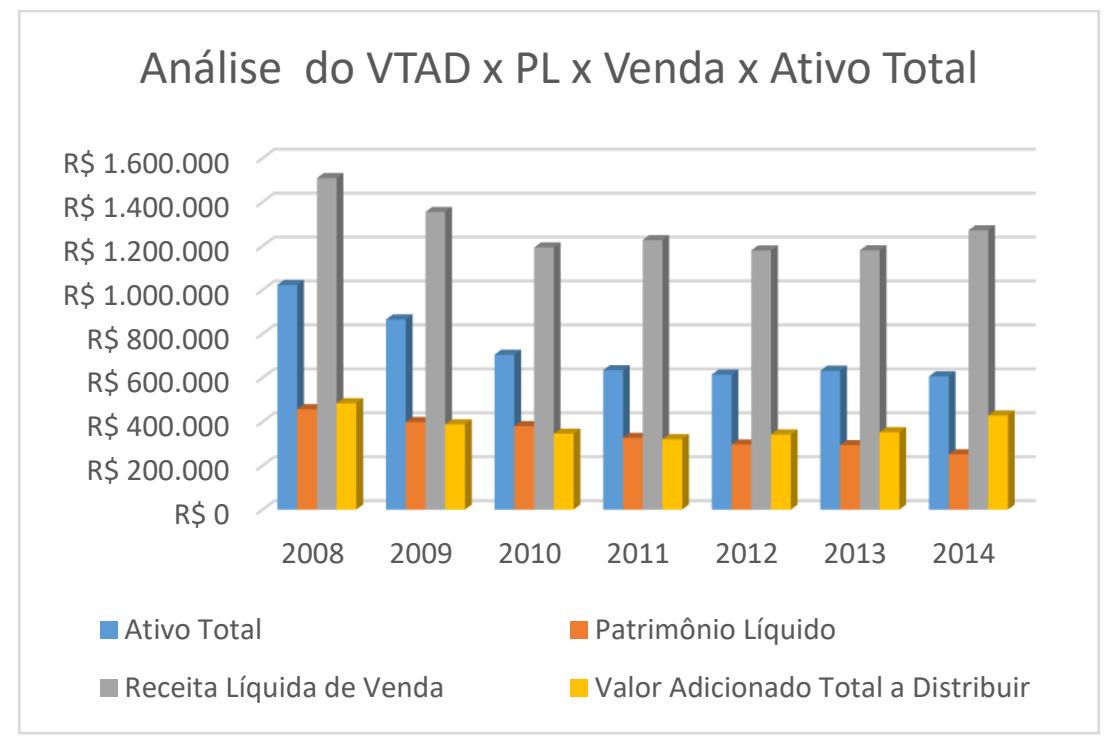

Fonte: Elaborado pela autora com base nos dados da pesquisa (2015).

Como nos anos de 2008 a 2014, o valor adicionado a distribuir aumentou e ativo total reduziu então cresceu a capacidade do ativo de gerada de riqueza.

Como a Venda diminuiu e o valor adicionado total adicionado diminuíram então o ganho econômico da riqueza diminuiu consequentemente.

\section{CONSIDERAÇÕES FINAIS}

Esta pesquisa buscou mostrar a relevância da DVA como instrumento informativo do quanto de riqueza as organizações produziram e de que forma essa riqueza foi distribuída por elas. Para dar continuidade a tal objetivo, essa demonstração monta um cenário que serve como ferramenta ideal para análises comparativas.

Por meios dos dados obtidos, verificou-se uma diminuição no valor adicionado nos anos de 2008 a 2013 e um pequeno aumento 2014 na empresa J Macêdo.

Na empresa M Dias Brancos, obteve um aumento significativo nos anos de 2008 a 2014 do valor adicionado.

Através da DVA identifica-se como a riqueza criada foi distribuída. Comprava-se que, por meio da análise dos indicadores de geração riqueza, de distribuição de riqueza e dos 
setoriais, anteriormente anexadas que o valor adicionado total a distribuir aumentou em uma das empresas e na outra diminuiu ao longo dos anos. Observa-se também que os valores dos Ativos Totais diminuíram nas duas empresas. O valor do Patrimônio Líquido e as Receitas Líquidas das empresas diminui em ambos os casos.

Como proposta final, possibilita-se a continuidade da pesquisa para a expansão em outras áreas industriais ou do ramo alimentício em outros estados. Vale-se ressaltar que a pesquisa foi limita a duas empresas cearenses pois as demais industrias do ramo alimentício não publicam a DVA.

\section{REFERÊNCIAS}

ALMEIDA, Renato Lopes de; SILVA, Adolfo Henrique Coutinho e Silva. Demonstração do Valor Adicionado (DVA): Uma análise de sua comparabilidade após tornar-se obrigatória no Brasil. Revista de Contabilidade do Mestrado em Ciências Contábeis da UERJ (online), Rio de Janeiro, v. 19, n. 1, p. 95 - p. 110, jan/abr., 2014. ISSN 1984-3291.

ALMEIDA, N.S; MARTINS, V.F; ALMEIDA, L.S.; SOARES, M.J.F. A utilização da Demonstração do valor adicionado na análise da produção e distribuição de riqueza entre os stakeholders: Um estudo de caso da Petrobras. RIC - Revista de Informação Contábil - ISSN 1982-3967 - Vol. 3, no 1, p. 134-148, Jan-Mar/2009.

BRASIL, Lei n 6.404/1976. Dispõe sobre as sociedades por ações. Disponível em: <http://www.planalto.gov.br/ccivil_03/leis/16404consol.htm>. Acesso em: agosto 2015.

CPC. Comitê de Pronunciamentos Contábeis. CPC 26. Disponível em: <http://static.cpc.mediagroup.com.br/Documentos/312_CPC_26_R1_rev\%2006.pdf〉. Acesso em: setembro 2015.

CUNHA, Jaqueline Veneroso Alves; RIBEIRO, Maisa de Souza; SANTOS, Ariovaldo dos. A Demonstração do Valor Adicionado como Instrumento de Mensuração da Distribuição da Riqueza, Revista Contabilidade \& Finanças, n. 37, p. 7-23, 2005.

DE LUCA, M. M. M. Demonstração do Valor Adicionado: Do cálculo da riqueza criada pela empresa ao valor do PIB. 2. ed. São Paulo, Atlas, 2009.

DELIBERAÇÃO da Comissão de Valores Mobiliários. 675/2011. Disponível em: <http://www.cvm.gov.br/export/sites/cvm/legislacao/anexos/deli/0600/deli675.pdf>. Acesso em: setembro 2015.

DELIBERAÇÃO CVM 557/2008. Disponível em:

<http://www.normaslegais.com.br/legislacao/deliberacaocvm557_2008.htm>. Acesso em: setembro 2015. 
KLOPPEL, Fábio Vilson; SCHNORRENBERGER Darci. ANÁLISE DA GERAÇÃO E DISTRIBUIÇÃO DA RIQUEZA GERADA PELASEMPRESAS QUE COMPÕE O IBOVESPA POR MEIO DA DVA. Florianópolis, Artigo Científico,2011.

FIPECAFI, Manual de Contabilidade das Sociedades por Ações. 3. ed. São Paulo: Atlas, 2003.

GIL, A. C. Como elaborar projetos de pesquisa. 3.ed.São Paulo, Atlas, 1996.

GUERRA, Luciano. A nova contabilidade: convergência ao padrão internacional.2.ed.São Paulo: Atlas, 2015.

GOUVEIA, F. Indústria de alimentos: no caminho da inovação e de novos produtos.

Inovação Uniemp, Campinas, v.2, n.5, dic. 2006.

IUDÍCIBUS, S. de; MARTINS, E.; GELBCKE, E. R. Manual de Contabilidade das Sociedades por Ações. 5ed., São Paulo: Atlas, 2000.

IUDÍCIBUS, S. de; MARTINS, E.; GELBCKE, E. R.; SANTOS, A. dos S. Manual de Contabilidade Societária. São Paulo: Atlas, 2010.

IUDÍCIBUS, Sergio de. Teoria da Contabilidade.7ed.São Paulo: Atlas, 2004.

IDÍCIBUS, S. de; MARION, J. C.: FARIA; A. C. de. Introdução para Contabilidade: Para Nível de Graduação.5. ed. São Paulo: Atlas, 2009.

LATORRACA, N. Direito tributário: Imposto de Renda das empresas. 13. Ed. São Paulo: Atlas, 2000.

OLIVEIRA, L. M. de; CHIEREGATO R.; JUNIOR J. H. P.; GOMES, M. B. G. Manual de Contabilidade Tributária. 13.ed.São Paulo. Saraiva, 2014.

KROETZ, César Eduardo Stenves. Balanço Social, teoria e prática. São Paulo: Atlas, 2000. MARCONI, M. de A.; LAKATOS, E. M. Metodologia do Trabalho Científico: Procedimentos básico; Pesquisa bibliográfica, projetos e relatórios; Publicação e trabalhos Científicos.6. ed. São Paulo, 2001.

MARION, José Carlos. Análise das Demonstrações Contábeis: Contabilidade Empresarial. 3 ed. São Paulo: Atlas, 2005.

MENDES, Wagner. Ativo Intangível (CPC04) e Ativo Imobilizado (CPC27). São Paulo: IOB, 2011. v. 4. (Coleção IFRS).

PADOVEZE, L. C. Manual de Contabilidade Básica, São Paulo Editora Atlas S.A-2009. RIBEIRO, Osni Moura. Contabilidade Intermediária. 2 ed. São Paulo: Saraiva, 2009. RIBEIRO, O. M. Contabilidade Intermediária, 2 ed. São Paulo. Saraiva. 2012. P.409 a 413. 
SANTOS, Ariovaldo dos. Demonstração do valor adicionado-DVA: um instrumento para mediação da geração e distribuição de riqueza das empresas/ Ariovaldo dos Santos. São Paulo: FEA/USP,1999. Tese (Doutorado) - Universidade de São Paulo

VICECONTI, P.; NEVES, das N. Contabilidade Avançada e análise das demonstrações

financeiras.16 ed. São Paulo: Saraiva, 2013.

Norma Brasileira de Contabilidade NBC T.3 - Conceito, Conteúdo, Estrutura e

Nomenclatura das Demonstrações. NBC T3.2. Disponível em:

http://www1.cfc.org.br/sisweb/sre/detalhes_sre.aspx?codigo=1990/000686

REIS, Arnaldo Carlos de Rezende. Demonstrações contábeis: estrutura e análise. 3ed. São Paulo: Saraiva,2009.

WELTER, Francisco; MISSAGIA, Luiz Roberto. Contabilidade avançada: teoria e questões comentadas. $4^{\mathrm{a}}$ ed. Rio de Janeiro: Campus,2011. 